\title{
Assessment of prescribing potentially inappropriate medications listed in Beers criteria and its association with the unplanned hospitalization: a cross-sectional study in Lahore, Pakistan
}

This article was published in the following Dove Press journal: Clinical Interventions in Aging

Muhammad Rehan Sarwar ${ }^{1,2}$

Abdur-Rehman Dar ${ }^{2}$

Saad Yousaf Mahar ${ }^{2}$

Tayyab Riaz ${ }^{2}$

Usman Danish ${ }^{2}$

Sadia Iftikhar ${ }^{2}$

'Department of Pharmacy, The Islamia University of Bahawalpur, Punjab, Pakistan; ${ }^{2}$ Department of Pharmacy Practice, Akhtar Saeed College of Pharmaceutical Sciences, Lahore, Pakistan
Correspondence: Muhammad Rehan Sarwar

Department of Pharmacy, The Islamia University of Bahawalpur, Punjab, 63100, Pakistan

Tel +92334456 6000

Email rehansarwaralvi@gmail.com
Background and objectives: Due to physiological and pharmacological variations, geriatrics are at high risk of experiencing life-threatening outcomes related to the use of potentially inappropriate medications (PIMs). Thus, the present study aims to evaluate prescribing practices of PIMs among elderly patients who may lead to unplanned hospitalization and associated risk factors.

Methods: A cross-sectional study was conducted in different hospitals of Lahore, Pakistan. The study population consisted of geriatric patients aged $\geq 65$ years. Data were collected from the medical records of geriatric patients, who attended these selected hospitals between December 1, 2017, and February 28, 2018. Data were analyzed using SPSS (IBM SPSS Statistics for Windows, Version 21.0) and Microsoft Excel (MS Office 2010).

Results: The records of 385 geriatric patients were investigated. More than half $(60.8 \%)$ of the patients were subjected to polypharmacy, which can be defined as the utilization of 5-9 drugs by the patient at the same time, whereas $36.4 \%$ were prescribed with one PIM and $56.4 \%$ were hospitalized due to PIMs. Majority of them were prescribed with PIMs including N02BA01 (aspirin, 32.4\%), A02BC01 (omeprazole, 23.6\%), A10AB02 (insulin, 17.4\%), A02BC05 (esomeprazole, 8.5\%), C08CA01 (amlodipine, 8.3\%), and R06AA02 (diphenhydramine, 5.9\%). Results of regression analysis revealed that patients exposed to polypharmacy $(\mathrm{OR}=2.556$, 95\% CI $=1.579-4.135, P$-value $\leq 0.001)$ and excessive polypharmacy $(\mathrm{OR}=37.828,95 \%$ $\mathrm{CI}=4.754-300.9, P$-value $\leq 0.001)$ were significantly associated with unplanned hospitalization, whereas factors such as age $75-84$ years $(\mathrm{OR}=0.343,95 \% \mathrm{CI}=0.156-0.756, P$-value $=0.008)$ and polypharmacy $(\mathrm{OR}=2.480,95 \% \mathrm{CI}=1.219-5.048, P$-value $=0.012)$ were significantly correlated with PIMs.

Conclusion: The utilization of PIMs listed in Beers criteria among geriatric population can cause unplanned hospitalization. As the patients receiving polypharmacy are at high risk of unplanned hospitalization, so caution must be exercised in prescribing PIMs for elderly people.

Keywords: Beers criteria, geriatrics, potentially inappropriate medications, unplanned hospitalization, polypharmacy

\section{Introduction}

The use of healthcare resources among geriatric population is tremendously high because the number of patients aged $>65$ years is unprecedentedly increasing all over the globe. ${ }^{1,2}$ Improving and maintaining the functional status are the cornerstone of geriatric pharmacotherapy, which can cure or palliate disease as well as enhance health-related quality of 
life. The rise in the number of comorbidities, polypharmacy, and age-related physiological changes (hepatic and nephrotic functioning, mental status, efficiency of heart, narrowing of vessels, fragility of bones, and weakness of body) alter the pharmacodynamics and pharmacokinetics of drugs due to which geriatrics are more susceptible of developing adverse drug events (ADEs). ${ }^{3-9}$ Therefore, the risk of an unexpected admission for managing health-related issues (eg, severe disease and treatment-related event) that cannot be controlled in the outpatient setting has dramatically increased, and it is named as "unplanned hospitalization". ${ }^{10}$

The term potentially inappropriate medications (PIMs) encompasses the use of such therapeutic agents whose risk may outweigh their potential benefits, especially when more efficacious pharmacological alternatives are available. A prospective study conducted in India revealed that nearly one-third of the geriatric population was prescribed with at least one PIM. ${ }^{11}$ Similarly, a study conducted in New Zealand suggested that PIMs were utilized by $42.7 \%$ of the community-dwelling elderly patients. ${ }^{12}$ Thus, such practices may increase the risk of developing ADEs up to several folds. ${ }^{13}$ This problem has threatened the geriatric population all over the world. For instance, every year 1 million older adults associated with potential ADEs are hospitalized in the USA. ${ }^{14,15}$ Another study also found that those elderly patients who were prescribed with PIMs had experienced hospitalization due to the development of adverse health outcomes. ${ }^{16}$ Similar estimations have been made for senior citizens in Australia where medication-associated unplanned hospitalization annually accounts for $15 \%-22 \%$ of the geriatric patients. ${ }^{17}$ Such circumstances may economically burden the healthcare system. Thus, for ensuring patient's safety, improving the quality of life (QoL), and decreasing the drug-related mortalities and morbidities, the medications included in PIMs must be contraindicated for people of this age group. ${ }^{18-23}$ For this reason, American Geriatric Society has developed guidelines, which are named as Beers Criteria for PIM Use in Older Adults. , 24-26 $^{2}$

Elderly population is growing at much faster rate. The census conducted between 1990 and 2010 in Pakistan revealed that geriatric population has increased by $75.1 \%{ }^{27}$ In 1998 , it was also reported by the WHO that the population aged $\geq 65$ years represents $5.6 \%$ of the entire population of Pakistan with a probability increasing to $11 \%$ by the year $2025 .^{28}$ In the developing world, a demographic rise in the number of geriatrics and the availability of scarce literature on PIMs indicate a need for studies in this area. These studies provide a landmark for stakeholders in making policies, determining the impact of medicines on community level and prioritizing the medical needs. The previously published studies conducted on different regions of the world have showed the effect of using Beers criteria as a guide demonstrated an increasing trend in the use of PIMs. However, it is still ambiguous that whether the utilization of PIMs listed in Beers criteria can lead to the development of ADEs in the elderly people or not, but in Pakistan, there is a scarcity of available literature on zonal, provincial, and national levels that give an insight about the consumption of PIMs by the geriatric patients. Hence, till date no clear estimation can be drawn about PIM-associated unplanned hospitalization of older adults. The aim of the present study is set to find the prescribing pattern of PIMs listed in Beers criteria among geriatric patients that leads to unplanned hospitalization. Also, the risk factors that influence the prescribing of PIMs among this age group have also been evaluated.

\section{Methods \\ Study design}

A quantitative, observational, cross-sectional, and prospective study was conducted in different hospitals of Lahore, Punjab, Pakistan, to scrutinize the prescribing patterns of PIMs and unplanned hospitalizations among the elderly hospitalized patients.

\section{Study settings}

The healthcare settings were randomly selected. Data were collected between December 1, 2017, and February 28, 2018, according to the objectives of the study. These selected settings were tertiary care public and private hospitals where inpatient healthcare services were provided to the patients aged $\geq 65$ years. These were comparable in terms of staff, services, and availability of formulary medicines; thus, healthcare professionals followed the same prescribing practices. Hence, randomly selected patients from these tertiary care hospitals would have minimal chances of significant bias.

\section{Study population and sample size}

According to latest Pakistani census, the total population living in Pakistan is 201,995,540. Lahore is the capital city of Punjab province and the second largest city of Pakistan with an estimated population of $11,126,285$ people. ${ }^{29}$ Using the Raosoft sample size calculator, ${ }^{30}$ the minimum obligatory sample size was 385 with $95 \% \mathrm{CI}$ and $5 \%$ margin of error:

$$
n=\frac{N x}{((N-1) E 2+x)}
$$


where $n$ is the population size, $x$ is the CI, and $E$ is the margin of error. Records of those patients who were aged $\geq 65$ years, chronically ill, and hospitalized for $>7$ days were included in the study, whereas the records of all those geriatric patients who were hospitalized on a planned basis for acute illness, exacerbation of chronic diseases or infections, end-stage lifethreatening diseases, providing pre- and postsurgery medical care, palliative care, and short-term prognosis, and who had incomplete medical records were excluded.

\section{Data collection}

A data collection form consisting of the following five major parts was designed: 1) demographic characteristics; 2) socioeconomic characteristics; 3) health-related characteristics; 4) clinical indications; and 5) past medication history. SPSS Version 21.0 (IBM Corporation, Armonk, NY, USA) was used for the calculation of reliability coefficients. Internal consistency was measured by Cronbach's $\alpha$, while reproducibility was evaluated by using intraclass correlation for each item in the scales, with acceptable values $\geq 0.6$. The Cronbach's $\alpha$ value was 0.74 demonstrating the excellent reliability. A pilot study was undertaken between October and November 2017 for pretesting the study instrument.

\section{Measurements}

\section{Demographic characteristics}

The following characteristics were evaluated in the demographic data of selected patients: gender (male/female), age (65-74, 75-84, and $\geq 84$ years), and civil status (single, married, widowed, and divorced).

\section{Socioeconomic characteristics}

The socioeconomic characteristics were education level (illiterate, primary, matriculation, intermediate, and graduate), employment status (employed, unemployed, and retired), annual income (low class, middle class, and upper class), and residence (rural and urban). Those patients who were unemployed but received revenue from their lands, business, or received pensions were considered as employed.

\section{Health-related characteristics}

Prescriptions were used to collect medical data while patients' attendants were consulted for demographic, socioeconomic, and health-related data. Health-related characteristics included following parameters: self-reported health (good, moderate, and poor), health service utilization (normal clinic visit $\leq 3 /$ year and high clinic visit $\geq 4$ /year), health risks (smoking, alcohol consumption, and obesity), and comorbidities (present and absent), which included chronic diseases such as diabetes mellitus, coronary vascular disease, respiratory disorders, gastrointestinal disorders, joint diseases, hypertension, and central nervous system disorders. Body mass index (BMI) was used to determine obesity, and patients were considered as normal $\left(\mathrm{BMI}<25 \mathrm{~kg} / \mathrm{m}^{2}\right)$, over weight $\left(25 \leq \mathrm{BMI}<30 \mathrm{~kg} / \mathrm{m}^{2}\right)$, or obese $\left(\mathrm{BMI} \geq 30 \mathrm{~kg} / \mathrm{m}^{2}\right) .{ }^{31}$

\section{Drug utilization evaluation}

After surveying, all the medicines were enlisted on the Performa. Anatomical Therapeutic Chemical classification system was used for the estimation of drug utilization patterns. $^{32}$ The active substances mostly prescribed were classified as low (prescribed to $<10 \%$ of selected patients), medium (prescribed to $\geq 10 \%$ of selected patients but $<40 \%$ ), and high (prescribed to $>40 \%$ of selected patients).

\section{PIMs' evaluation}

For examining PIMs, medicines prescribed to the selected patients were evaluated according to the 2015 Beers criteria. ${ }^{33}$ Detection of PIMs was based on past medication history of patients who were hospitalized for $>7$ days. All the drugs mentioned in the past medication history were checked for appropriateness with respect to indications and interactions. Disease-dependent PIMs were defined on the basis of International Classification of Diseases, Ninth Revision, Clinical Modification (ICD-9-CM) codes. ${ }^{34}$ The expert opinions of physicians and clinical pharmacists were also taken in account before reaching the final decision.

\section{Unplanned hospitalization evaluation}

All those selected cases were referred to as "unplanned hospitalization" in which patients visited the emergency department, but within 24 hours, their clinical sign and symptoms did not show any improvement, and there had been the need of further investigation or treatment that compelled the healthcare professionals to admit them in the inpatient ward directly from the emergency room. Therefore, the profile of all the selected participants was scrutinized to check the clinical presentation and diagnostic tests' results at the time of their visit to the emergency room as well as unplanned admission in the inpatient ward. On the basis of diagnostic findings and the sound clinical judgment of physicians and clinical pharmacists, if the possibility of unplanned hospitalization due to underlying diseases was ruled out, then the patients were asked to show their all prescriptions and pertinent laboratory test results as well as diagnostic findings 1 month prior to their hospitalization. All the information 
pertaining to drug utilization before unplanned hospitalization was then confirmed by the patient's attendants. Based on past medical history, any such drug was said to be PIM if it must be contraindicated to the patient according to Beers criteria. In this way, the utilization of any PIM by the patients within 1 month prior to their unplanned hospitalization was checked.

\section{Statistical analysis}

SPSS (IBM Corporation Released 2012, IBM SPSS Statistics for Windows Version 21.0) and Microsoft Excel (MS Office 2010) were used for data analysis. Descriptive statistics such as frequencies and percentages was used to present the data. Furthermore, logistic regression analysis was performed to evaluate the factors associated with the prescribing pattern of PIMs among geriatric patients. Results were expressed as OR accompanied by $95 \% \mathrm{CIs}$, and a $P$-value of $<0.05$ was used for statistical significance of differences.

\section{Ethics approval and consent to participate}

Ethical approval including verbal informed consent process was obtained from Pharmacy Research Ethics Committee at Akhtar Saeed College of Pharmaceutical Sciences, Lahore (reference: 08-2017/PREC, September 22, 2017). Before conducting the study, permission was granted from the hospital administrators. The purpose and protocols of this study were thoroughly explained to every participant, and their verbal consents were obtained. Written consent was not possible for most of the respondents because either they were illiterate or they had problems in reading and/or signing the consent document.

\section{Results}

A total of 419 elderly hospitalized patients in government and private hospitals of Lahore were approached and 385 consented patients (response rate $=91.8 \%$ ) were included according to the inclusion and exclusion criteria.

A total of $66.2 \%(n=255)$ of the participants were male, and $68.1 \%(\mathrm{n}=262)$ were aged $65-74$ years. Over three quarters $(81.0 \%, \mathrm{n}=312)$ were married, just over one-third $(39.0 \%$, $\mathrm{n}=150)$ were illiterate, and $31.2 \%(\mathrm{n}=120)$ were of low annual income. Little over one-half $(54.0 \%, \mathrm{n}=208)$ were employed and $66.0 \%(n=254)$ were urban residents. Self-reported health was moderate in $60.0 \%(n=231)$, whereas $55.3 \%(n=213)$ had attended $\geq 3$ clinic visits in the previous year. A total of $44.7 \%(n=172)$ were smokers, and comorbidity was present in over three quarters $(76.6 \%, \mathrm{n}=295)$ of the participants.
A total of $60.8 \%(n=234)$ were subjected to polypharmacy (5-9 drugs), while 36.4\% $(n=140)$ were prescribed with one PIM and just over one-half $(56.4 \%, n=217)$ were hospitalized due to PIMs (Table 1).

Table I Characteristics of the participants

\begin{tabular}{|c|c|c|c|}
\hline Variables & $\begin{array}{l}\text { Male } \\
(n=255), \\
n(\%)\end{array}$ & $\begin{array}{l}\text { Female } \\
(n=130) \\
n(\%)\end{array}$ & $\begin{array}{l}\text { Total } \\
(\mathbf{N}=385), \\
n(\%)\end{array}$ \\
\hline \multicolumn{4}{|l|}{ Age (years) } \\
\hline $65-74$ & $163(42.3)$ & 99 (25.7) & $262(68.1)$ \\
\hline $75-84$ & $74(19.2)$ & $27(7.0)$ & $101(26.2)$ \\
\hline$\geq 85$ & $18(4.7)$ & $4(1.0)^{\prime}$ & $22(5.7)$ \\
\hline \multicolumn{4}{|l|}{ Civil status } \\
\hline Single & $9(2.3)$ & $\mathrm{I}(0.3)$ & $10(2.6)$ \\
\hline Married & $200(51.9)$ & $112(29.1)$ & $312(81)$ \\
\hline Widow & $40(10.4)$ & 15 (3.9) & $55(14.3)$ \\
\hline Divorced & $6(1.6)$ & $2(0.5)$ & $8(2.15)$ \\
\hline \multicolumn{4}{|l|}{ Education level } \\
\hline Primary & $47(12.2)$ & $16(4.2)$ & $63(16.4)$ \\
\hline Matriculation & $84(21.8)$ & $26(6.8)$ & $110(28.6)$ \\
\hline Intermediate & $14(3.6)$ & $5(1.3)$ & $19(4.9)$ \\
\hline Graduate & $33(8.6)$ & $10(2.6)$ & $43(11.2)$ \\
\hline Illiterate & $77(20)$ & $73(19)$ & $150(39)$ \\
\hline \multicolumn{4}{|l|}{ Employment status } \\
\hline Employed & $192(49.9)$ & $16(4.2)$ & $208(54)$ \\
\hline Unemployed & $63(16.4)$ & $114(29.6)$ & 177 (46) \\
\hline \multicolumn{4}{|l|}{ Annual income } \\
\hline Low class & $110(28.6)$ & $10(2.6)$ & $120(3 \mid .2)$ \\
\hline Middle class & $60(15.6)$ & $3(0.8)$ & $63(16.4)$ \\
\hline Upper class & $26(6.8)$ & $7(1.8)$ & $33(8.6)$ \\
\hline \multicolumn{4}{|l|}{ Residence } \\
\hline Rural & $86(22.3)$ & 45 (II.7) & $|3|$ (34) \\
\hline Urban & 169 (43.9) & $85(22.1)$ & $254(66)$ \\
\hline \multicolumn{4}{|l|}{ Self-reported health } \\
\hline Good & $19(4.9)$ & $10(2.6)$ & $29(7.5)$ \\
\hline Moderate & 151 (39.2) & $80(20.8)$ & $231(60)$ \\
\hline Poor & $85(22.1)$ & $40(10.4)$ & $125(32.5)$ \\
\hline \multicolumn{4}{|l|}{ Health service utilization } \\
\hline Normal clinic visit ( $\leq 3 /$ year) & $117(30.4)$ & $55(14.3)$ & I 72 (44.7) \\
\hline High clinic visit ( $\geq 4 /$ year) & $138(35.8)$ & $75(19.5)$ & $213(55.3)$ \\
\hline \multicolumn{4}{|l|}{ Health risks } \\
\hline Smoking & $163(42.3)$ & $9(2.3)$ & I 72 (44.7) \\
\hline Alcohol consumption & $\mathrm{I}(0.3)$ & $0(0.0)$ & $\mathrm{I}(0.3)$ \\
\hline Obesity & 44 (II.4) & $50(13.0)$ & $94(24.4)$ \\
\hline None & $47(12.2)$ & 7I (18.4) & I I 8 (30.6) \\
\hline \multicolumn{4}{|l|}{ Comorbidity } \\
\hline Present & $197(5 \mid .2)$ & $98(25.5)$ & $295(76.6)$ \\
\hline Absent & $58(15.1)$ & $32(8.3)$ & $90(23.4)$ \\
\hline \multicolumn{4}{|l|}{ Number of drugs } \\
\hline$\leq 4$ & $76(19.7)$ & $5 I(13.2)$ & $127(33.0)$ \\
\hline Polypharmacy (5-9) & $162(42.1)$ & $72(18.7)$ & $234(60.8)$ \\
\hline Excessive polypharmacy $(\geq 10)$ & $17(4.4)$ & $7(1.8)$ & $24(6.2)$ \\
\hline \multicolumn{4}{|l|}{ Number of PIMs } \\
\hline I & $88(22.9)$ & $52(13.5)$ & I 40 (36.4) \\
\hline 2 & $90(23.4)$ & $36(9.4)$ & $126(32.7)$ \\
\hline 3 & $34(8.8)$ & $20(5.2)$ & $54(14.0)$ \\
\hline 4 & $10(2.6)$ & $6(1.6)$ & $16(4.2)$ \\
\hline 5 & $2(0.5)$ & $2(0.5)$ & $4(1.0)$ \\
\hline 6 & $\mathrm{I}(0.3)$ & $\mathrm{I}(0.3)$ & $2(0.5)$ \\
\hline \multicolumn{4}{|l|}{ Unplanned hospitalization } \\
\hline No & $110(28.6)$ & $58(15.1)$ & $168(43.6)$ \\
\hline Yes & $145(37.7)$ & 72 (I8.7) & $217(56.4)$ \\
\hline
\end{tabular}

Abbreviation: PIMs, potentially inappropriate medications. 
Table 2 Indications associated with elderly hospitalized patients

\begin{tabular}{lllll}
\hline $\begin{array}{l}\text { Serial } \\
\text { number }\end{array}$ & Indications & $\begin{array}{l}\text { Male } \\
(\mathbf{n}=\mathbf{2 5 5}), \\
\mathbf{n}(\%)\end{array}$ & $\begin{array}{l}\text { Female } \\
(\mathbf{n}=1 \mathbf{3 0}), \\
\mathbf{n}(\%)\end{array}$ & $\begin{array}{l}\text { Total } \\
\mathbf{( N = 3 8 5 ) ,} \\
\mathbf{n}(\%)\end{array}$ \\
\hline 1 & CVS and blood related & $138(54.1)$ & $66(50.7)$ & $204(52.9)$ \\
2 & CNS & $27(10.5)$ & $15(11.5)$ & $42(10.9)$ \\
3 & GIT & $37(14.5)$ & $25(19.2)$ & $62(16.1)$ \\
4 & Respiratory & $112(43.9)$ & $55(42.3)$ & $167(43.3)$ \\
5 & Kidney & $18(7.0)$ & $17(13.0)$ & $35(9.09)$ \\
6 & Joint and muscles related & $16(6.2)$ & $10(7.6)$ & $26(6.7)$ \\
7 & Endocrinology and & $76(29.8)$ & $45(34.6)$ & $121(31.4)$ \\
& metabolic disorders & & & \\
8 & Others & $42(16.4)$ & $24(18.4)$ & $66(17.1)$ \\
\hline
\end{tabular}

Abbreviations: CVS, cardiovascular system; CNS, central nervous system; GIT, gastrointestinal tract.

The most common indications among hospitalized patients were CVS and blood-related disorders (52.9\%), respiratory disorders $(43.3 \%)$, and endocrinology and metabolic disorders (31.4\%) (Table 2).

The most commonly prescribed PIMs were N02BA01 (aspirin, $\mathrm{n}=125,32.4 \%$ ), A02BC01 (omeprazole, $\mathrm{n}=91$, $23.6 \%$ ), A10AB02 (insulin, $\mathrm{n}=67,17.4 \%$ ), $\mathrm{A} 02 \mathrm{BC} 05$ (esomeprazole, $\mathrm{n}=33,8.5 \%$ ), C08CA01 (amlodipine, $\mathrm{n}=32$, $8.3 \%$ ), and R06AA02 (diphenhydramine, $\mathrm{n}=23,5.9 \%$ ) (Table 3).

\section{Determinants associated with PIMs and unplanned hospitalization}

Logistic regression analysis evaluated the association of both PIMs and unplanned hospitalization with the independent variables of study participants. Results revealed that patients aged $75-84$ years had $65.7 \%$ less PIMs $(\mathrm{OR}=0.343$, $95 \% \mathrm{CI}=0.156-0.756, P$-value $=0.008)$ compared with those aged 65-74 years. While examining the association between number of drugs and PIMs, polypharmacy (5-9 drugs) had 2.480 times more PIMs (OR=2.480, 95\% CI=1.219-5.048, $P$-value $=0.012)$ as compared with those utilizing $\leq 4$ medicines (Table 4).

Furthermore, results of logistic regression analysis examined the association between independent variables and unplanned hospitalization revealing that polypharmacy (5-9 drugs) had 2.556 times more hospitalization (OR=2.556, $95 \% \mathrm{CI}=1.579-4.135, P$-value $\leq 0.001)$ and excessive polypharmacy ( $\geq 10$ drugs) had 37.828 times more hospitalization $(\mathrm{OR}=37.828,95 \% \mathrm{CI}=4.754-300.9, P$-value $\leq 0.001)$ compared with those utilizing $\leq 4$ medicines (Table 5 ).

\section{Discussion}

The findings of this study revealed that prior to unplanned hospitalization, most of the patients were prescribed with
PIMs including aspirin, omeprazole, insulin, esomeprazole, amlodipine, and diphenhydramine and had been suffering from disorders of CVS, respiratory system, endocrine system, and metabolic system. Similar results were found from previously published study in Nepal where the cardiovascular drugs (eg, amlodipine) and antihistaminic agents (eg, diphenhydramine) were commonly prescribed to 23.16 and $4.6 \%$ of the elderly patients. ${ }^{35}$ A national survey in the USA described that the use of insulin among 206 elderly patients per 100,000 outpatient prescription visits is one of the major reasons for unplanned hospitalization because of its association with hypoglycemic events and seizures. ${ }^{36}$ Another study conducted in Karachi, Pakistan, had declared that at least one PIM was prescribed to $64 \%$ of the geriatric population..$^{37}$ It is estimated that antihistaminic agents (eg, diphenhydramine), proton pump inhibitors (eg, omeprazole and esomeprazole), and analgesics (eg, aspirin and nonsteroidal anti-inflammatory drugs) are more frequently used by elderly people than by any other age groups. ${ }^{38-40}$ This is probably due to the reason that old age people mostly suffer from insomnia, heart burn, acid reflex, headache, muscle pain, and joint pain due to multiple comorbidities and the physicians in developing countries such as Pakistan are usually inefficient in diagnosing the underlying cause. . $^{41,42}$ Also, there is no clinical guideline available in Pakistan for the diagnosis and management of diseases among geriatric patients. Although many international guidelines such as Beers criteria and STOP/START criteria are available for assisting in the selection of appropriate medication for this high-risk population, unfortunately these guidelines are poorly implemented in public and private healthcare settings of this region. ${ }^{43}$

Logistic regression analysis was used for establishing statistically significant association of PIMs and unplanned hospitalization with patient-related variables. Findings suggested that advanced age and exposure of patient with large number of medicines were the strong determinants of prescribing PIMs, while unplanned hospitalization was only significantly associated with polypharmacy. The correlation is in line with the study conducted in Brazil and Switzerland where elderly patients receiving polypharmacy are at higher risk of unplanned hospitalization. ${ }^{44,45}$ Based on a significant causal association, evidence suggested that the risk of unplanned hospitalization can be reduced up to $6 \%$ if PIMs are avoided among geriatric patients. ${ }^{46}$ Another study also demonstrated that elderly patients are more prone toward PIM-associated ADEs because of its significant association with polypharmacy. ${ }^{47}$ The possible explanation 
Table 3 PIMs prescribing pattern among study participants

\begin{tabular}{|c|c|c|c|c|c|c|}
\hline $\begin{array}{l}\text { Serial } \\
\text { number }\end{array}$ & Medicines & $\begin{array}{l}\text { ATC } \\
\text { code }\end{array}$ & $\begin{array}{l}\text { Male } \\
(n=255), \\
n(\%)\end{array}$ & $\begin{array}{l}\text { Female } \\
(n=130), \\
n(\%)\end{array}$ & $\begin{array}{l}\text { Total } \\
(\mathbf{N}=385), \\
n(\%)\end{array}$ & Trend \\
\hline $\mathrm{I}$ & Aspirin & N02BAOI & $86(33.7)$ & $39(30.0)$ & $125(32.4)$ & High \\
\hline 2 & Amlodipine & C08CAOI & $22(8.6)$ & $10(7.6)$ & $32(8.3)$ & Medium \\
\hline 3 & Alprazolam & N05BAI 2 & $9(3.52)$ & $6(4.6)$ & I5 (3.8) & Low \\
\hline 4 & Atropine & A03BA0I & $8(3.1)$ & $6(4.6)$ & $14(3.6)$ & Low \\
\hline 5 & Amitriptyline & N06AA09 & $0(0.0)$ & $0(0.0)$ & $0(0.0)$ & Low \\
\hline 6 & Aripiprazole & N05AXI2 & I $(0.3)$ & $0(0.0)$ & I $(0.2)$ & Low \\
\hline 7 & Chlorphenarimine & R06AB04 & $2(0.7)$ & $2(1.5)$ & $4(1.0)$ & Low \\
\hline 8 & Clonazepam & N03AE0I & $4(1.5)$ & $2(1.5)$ & $6(1.5)$ & Low \\
\hline 9 & Chlorzoxazone & М03ВВ03 & $2(0.7)$ & $0(0.0)$ & $2(0.5)$ & Low \\
\hline 10 & Caffeine & N06BCOI & $\mathrm{I}(0.3)$ & $0(0.0)$ & I $(0.2)$ & Low \\
\hline II & Clidinium & $\mathrm{A} 03 \mathrm{CA} 02$ & $0(0.0)$ & $0(0.0)$ & $0(0.0)$ & Low \\
\hline 12 & Chlorpromazine & N05AA0I & $0(0.0)$ & $2(1.5)$ & $2(0.5)$ & Low \\
\hline 13 & Diclofenac Sodium & MOIAB05 & $13(5.0)$ & $9(6.9)$ & $22(5.7)$ & Medium \\
\hline 14 & Dimenhydrinate & R06AA52 & $8(3.1)$ & $4(3.0)$ & $12(3.1)$ & Low \\
\hline 15 & Digoxin & C0IAA05 & $5(1.9)$ & $3(2.3)$ & $8(2.0)$ & Low \\
\hline 16 & Diphenhydramine & R06AA02 & $21(8.2)$ & $2(1.5)$ & $23(5.9)$ & Medium \\
\hline 17 & Diltiazem HCL & C08DB0I & $4(1.5)$ & I (0.7) & $5(1.2)$ & Low \\
\hline 18 & Dexamethasone & R0IAD03 & $7(2.7)$ & $4(3.0)$ & $11(2.8)$ & Low \\
\hline 19 & Doxazosin & $\mathrm{C} 02 \mathrm{CA} 04$ & $0(0.0)$ & I (0.7) & I $(0.2)$ & Low \\
\hline 20 & Ephedrine & R0IAA03 & $2(0.7)$ & $0(0.0)$ & $2(0.5)$ & Low \\
\hline 21 & Esomeprazole & $\mathrm{A} 02 \mathrm{BC} 05$ & $21(8.2)$ & $12(9.2)$ & $33(8.5)$ & Medium \\
\hline 22 & Famotidine & А02BA03 & I $(0.3)$ & $0(0.0)$ & I $(0.2)$ & Low \\
\hline 23 & Flurbiprofen & R02AX0I & I $(0.3)$ & $0(0.0)$ & I $(0.2)$ & Low \\
\hline 24 & Glimepiride & AIOBB 12 & $3(1.1)$ & $6(4.6)$ & $9(2.3)$ & Low \\
\hline 25 & Glibenclamide & AIOBBOI & $7(2.7)$ & $0(0.0)$ & $7(1.8)$ & Low \\
\hline 26 & Hydrocortisone & D07AA02 & $16(6.2)$ & $6(4.6)$ & $22(5.7)$ & Low \\
\hline 27 & Insulin & A10AB02 & $43(16.8)$ & $24(18.4)$ & $67(17.4)$ & High \\
\hline 28 & Ibuprofen & MOIAEOI & $4(1.5)$ & $0(0.0)$ & $4(1.0)$ & Low \\
\hline 29 & Ketorolac & MOIABI5 & I $(0.3)$ & $2(1.5)$ & $3(0.7)$ & Low \\
\hline 30 & Methylprednisolone & D07ACI4 & $2(0.7)$ & I (0.7) & $3(0.7)$ & Low \\
\hline 31 & Metoclopramide & A03FA0I & $5(1.9)$ & $2(1.5)$ & $7(1.8)$ & Low \\
\hline 32 & Maloxicam & MOIAC06 & $0(0.0)$ & $\mathrm{I}(0.7)$ & $\mathrm{I}(0.2)$ & Low \\
\hline 33 & Methocarbamol & М03ВА03 & $0(0.0)$ & $0(0.0)$ & $0(0.0)$ & Low \\
\hline 34 & Nifedipine & C08CA05 & $7(2.7)$ & I $(0.7)$ & $8(2.0)$ & Low \\
\hline 35 & Naproxen & M02AAI2 & $3(1.1)$ & $3(2.3)$ & $6(1.5)$ & Low \\
\hline 36 & Omeprazole & $\mathrm{A} 02 \mathrm{BC} 0 \mathrm{I}$ & $58(22.7)$ & $33(25.3)$ & 91 (23.6) & High \\
\hline 37 & Orphenadrine & N04AB02 & $10(3.9)$ & $6(4.6)$ & $16(4.1)$ & Low \\
\hline 38 & Piroxicam & MOIACOI & $4(1.5)$ & $6(4.6)$ & $10(2.5)$ & Low \\
\hline 39 & Promethazine & R06AD02 & $\mathrm{I}(0.3)$ & $0(0.0)$ & I $(0.2)$ & Low \\
\hline 40 & Prednisolone & Н02АВ06 & $9(3.5)$ & $9(6.9)$ & $18(4.6)$ & Low \\
\hline 41 & Peroxitine & N06AB05 & $3(1.1)$ & I (0.7) & $4(1.0)^{\prime}$ & Low \\
\hline 42 & Pentoprazole & $\mathrm{A} 02 \mathrm{BC} 02$ & $\mathrm{I}(0.3)$ & $2(1.5)$ & $3(0.7)$ & Low \\
\hline 43 & Ranatidine & A02BA02 & $12(4.7)$ & $7(5.3)$ & $19(4.9)$ & Low \\
\hline 44 & Rabeprazole & $\mathrm{A} 02 \mathrm{BC} 04$ & $4(1.5)$ & $2(1.5)$ & $6(1.5)$ & Low \\
\hline 45 & Resperidone & N06AX08 & I $(0.3)$ & I $(0.7)$ & $2(0.5)$ & Low \\
\hline 46 & Tramadol & $\mathrm{N} 02 \mathrm{~A} \times 02$ & II (4.3) & $7(5.3)$ & $18(4.6)$ & Low \\
\hline 47 & Theophylline & R03DA04 & $8(3.1)$ & $2(1.5)$ & $10(2.5)$ & Low \\
\hline
\end{tabular}

Abbreviations: ATC, Anatomical Therapeutic Chemical; PIMs, potentially inappropriate medications.

is that the multiple comorbidities tend the elderly patients to visit multiple physicians of various specialties and thus are at higher risk of prescribing various medicines especially from the list of Beers criteria. ${ }^{48}$ As the previously published studies, ${ }^{49-51}$ other factors including gender, comorbidities, and health service utilization were not found to be correlated with both PIMs and unplanned hospitalization, whereas some studies showed a significant association of female gender and comorbidities with the PIMs. ${ }^{50,52,53}$ This is merely because of the fact that comorbidities and gender differences may not 
Table 4 Logistic regression analysis of determinants associated with PIMs

\begin{tabular}{|c|c|c|c|c|c|}
\hline \multirow[t]{2}{*}{ Characteristics } & \multicolumn{2}{|c|}{ PIMs, n (\%) } & \multirow[t]{2}{*}{ OR } & \multirow[t]{2}{*}{$95 \% \mathrm{Cl}$} & \multirow[t]{2}{*}{$P$-value } \\
\hline & Yes & No & & & \\
\hline \multicolumn{6}{|l|}{ Gender } \\
\hline Male & $225(58.4)$ & $30(7.8)$ & 1.0 & - & - \\
\hline Female & $117(30.4)$ & $13(3.4)$ & 0.752 & $0.254-2.221$ & 0.606 \\
\hline \multicolumn{6}{|l|}{ Age (years) } \\
\hline $65-74$ & $237(6 \mathrm{I} .6)$ & $25(6.5)$ & 1.0 & - & - \\
\hline $75-84$ & $84(21.8)$ & $17(4.4)$ & 0.343 & $0.156-0.756$ & 0.008 \\
\hline$\geq 84$ & $21(5.5)$ & I (0.3) & 1.013 & $0.113-9.040$ & 0.991 \\
\hline \multicolumn{6}{|l|}{ Civil status } \\
\hline Single & $10(2.6)$ & $0(0.0)$ & 1.0 & - & - \\
\hline Married & $275(7 \mid .4)$ & $37(9.6)$ & 0.000 & $0.000-0.000$ & 0.999 \\
\hline Widow & $49(12.7)$ & $6(1.6)$ & 0.000 & $0.000-0.000$ & 0.999 \\
\hline Divorced & $8(2.1)$ & $0(0.0)$ & $\mathrm{I} .5 \mathrm{II}$ & $0.000-0.000$ & 1.00 \\
\hline \multicolumn{6}{|l|}{ Education level } \\
\hline Primary & $57(14.8)$ & $6(1.6)$ & 1.0 & - & - \\
\hline Matriculation & 91 (23.6) & $19(4.9)$ & 0.432 & $0.142-1.315$ & 0.140 \\
\hline Intermediate & $17(4.4)$ & $2(0.5)$ & 0.407 & $0.053-3.130$ & 0.388 \\
\hline Graduate & $39(10.1)$ & $4(1.0)$ & 0.418 & $0.067-2.597$ & 0.350 \\
\hline Illiterate & $138(35.8)$ & $12(3.1)$ & 0.898 & $0.280-2.886$ & 0.857 \\
\hline \multicolumn{6}{|l|}{ Employment status } \\
\hline Employed & I82 (47.3) & $26(6.8)$ & 1.0 & - & - \\
\hline Unemployed & $160(4 \mid .6)$ & $17(4.4)$ & 1.906 & $0.666-5.458$ & 0.229 \\
\hline \multicolumn{6}{|l|}{ Annual income } \\
\hline Low class & $254(66.0)$ & $35(9.1)$ & 1.0 & - & - \\
\hline Middle class & $58(15.1)$ & $5(1.3)$ & 2.886 & $0.842-9.888$ & 0.092 \\
\hline Upper class & $30(7.8)$ & $3(0.8)$ & 3.014 & $0.488-18.62$ & 0.235 \\
\hline \multicolumn{6}{|l|}{ Residence } \\
\hline Rural & II 8 (30.6) & $13(3.4)$ & 1.0 & - & - \\
\hline Urban & $224(58.2)$ & $30(7.8)$ & 0.986 & $0.432-2.253$ & 0.973 \\
\hline \multicolumn{6}{|l|}{ Self-reported health } \\
\hline Good & $23(6.0)$ & $6(1.6)$ & 1.0 & - & - \\
\hline Moderate & $204(53.0)$ & $27(7.0)$ & 2.030 & $0.664-6.203$ & 0.214 \\
\hline Poor & $115(29.9)$ & $10(2.6)$ & 2.480 & $0.650-9.460$ & 0.184 \\
\hline \multicolumn{6}{|l|}{ Health service utilization } \\
\hline Normal clinic visit ( $\leq 3 /$ year) & I5I (39.2) & $21(5.5)$ & 1.0 & - & - \\
\hline High clinic visit ( $\geq 4 /$ year) & $191(49.6)$ & $22(5.7)$ & 1.064 & $0.493-2.293$ & 0.875 \\
\hline \multicolumn{6}{|l|}{ Health risks } \\
\hline Smoking & $149(38.7)$ & $23(6.0)$ & 1.0 & - & - \\
\hline Alcohol consumption & I (0.3) & $0(0.0)$ & - & - & 1.000 \\
\hline Obesity & $84(21.8)$ & $10(2.6)$ & 1.343 & $0.498-3.624$ & 0.561 \\
\hline None & $108(28.1)$ & $10(2.6)$ & 1.727 & $0.617-4.834$ & 0.298 \\
\hline \multicolumn{6}{|l|}{ Comorbidity } \\
\hline Present & $266(69.1)$ & $29(7.5)$ & 1.0 & - & - \\
\hline Absent & $76(19.7)$ & $14(3.6)$ & 0.699 & $0.318-1.537$ & 0.374 \\
\hline \multicolumn{6}{|l|}{ Number of drugs } \\
\hline$\leq 4$ & $103(26.8)$ & $24(6.2)$ & 1.0 & - & - \\
\hline Polypharmacy (5-9) & $215(55.8)$ & $19(4.9)$ & 2.480 & $1.219-5.048$ & 0.012 \\
\hline Excessive polypharmacy $(\geq 10)$ & $24(6.2)$ & $0(0.0)$ & - & - & 0.998 \\
\hline
\end{tabular}

Note: Bold values show statistical significance of differences.

Abbreviations: $\mathrm{Cl}$, confidence interval; OR, odd ratio; PIMs, potentially inappropriate medications.

only influenced by biological differences, but severity of illness, social norms, cultural heritage, behavioral factors, and physiological dissimilarities have an impact on them. ${ }^{54}$ Moreover, other factors such as education (illiterate and literate), residence, and income levels were not found to be significantly associated with the prescribing practices of PIMs and unplanned hospitalization. Evidence suggested that the patients having low literacy skills and poor financial status are 1.5-3 times more likely to utilize PIMs and undergo unplanned hospitalization, ${ }^{55}$ but no such information was 
Table 5 Logistic regression analysis of determinants associated with unplanned hospitalization

\begin{tabular}{|c|c|c|c|c|c|}
\hline \multirow[t]{2}{*}{ Characteristics } & \multicolumn{2}{|c|}{ Unplanned hospitalization, $\mathbf{n}(\%)$} & \multirow[t]{2}{*}{ OR } & \multirow[t]{2}{*}{$95 \% \mathrm{Cl}$} & \multirow[t]{2}{*}{$P$-value } \\
\hline & Yes & No & & & \\
\hline \multicolumn{6}{|l|}{ Gender } \\
\hline Male & $145(37.7)$ & $110(28.6)$ & 1.0 & - & - \\
\hline Female & $72(18.7)$ & $58(15.1)$ & 1.022 & $0.516-2.024$ & 0.950 \\
\hline \multicolumn{6}{|l|}{ Age (years) } \\
\hline $65-74$ & $149(38.7)$ & $113(29.4)$ & 1.0 & - & - \\
\hline $75-84$ & $52(13.5)$ & $49(12.7)$ & 0.636 & $0.367-1.103$ & 0.107 \\
\hline$\geq 84$ & $16(4.2)$ & $6(1.6)$ & 1.405 & $0.468-4.218$ & 0.544 \\
\hline \multicolumn{6}{|l|}{ Civil status } \\
\hline Single & $6(1.6)$ & $4(1.0)$ & 1.0 & - & - \\
\hline Married & $169(43.9)$ & $143(37.1)$ & 0.513 & $0.126-2.093$ & 0.352 \\
\hline Widow & $34(8.8)$ & $21(5.5)$ & 0.603 & $0.133-2.734$ & 0.512 \\
\hline Divorced & $8(2.1)$ & $0(0.0)$ & - & - & 0.999 \\
\hline \multicolumn{6}{|l|}{ Education level } \\
\hline Primary & $38(9.9)$ & $25(6.5)$ & 1.0 & - & - \\
\hline Matriculation & $59(15.3)$ & $51(13.2)$ & 0.775 & $0.38 \mathrm{I}-1.578$ & 0.482 \\
\hline Intermediate & $9(2.3)$ & $10(2.6)$ & 0.438 & $0.122-1.577$ & 0.207 \\
\hline Graduate & $25(6.5)$ & $18(4.7)$ & 0.984 & $0.328-2.949$ & 0.976 \\
\hline Illiterate & $86(22.3)$ & $64(16.6)$ & 0.802 & $0.403-1.594$ & 0.528 \\
\hline \multicolumn{6}{|l|}{ Employment status } \\
\hline Employed & II 17 (30.4) & 9I (23.6) & 1.0 & - & - \\
\hline Unemployed & $100(26.0)$ & $77(20.0)$ & 1.099 & $0.56 \mathrm{I}-2.154$ & 0.783 \\
\hline \multicolumn{6}{|l|}{ Annual income } \\
\hline Low class & $163(42.3)$ & $126(32.7)$ & 1.0 & - & - \\
\hline Middle class & $38(9.9)$ & $25(6.5)$ & 1.207 & $0.587-2.485$ & 0.609 \\
\hline Upper class & $16(4.2)$ & $17(4.4)$ & 0.615 & $0.199-1.899$ & 0.398 \\
\hline \multicolumn{6}{|l|}{ Residence } \\
\hline Rural & $75(19.5)$ & $56(14.5)$ & 1.0 & - & - \\
\hline Urban & I 42 (36.9) & $112(29.1)$ & 0.751 & $0.449-1.257$ & 0.277 \\
\hline \multicolumn{6}{|l|}{ Self-reported health } \\
\hline Good & $17(4.4)$ & $12(3.1)$ & 1.0 & - & - \\
\hline Moderate & $121(31.4)$ & $110(28.6)$ & 0.620 & $0.257-1.49$ & 0.287 \\
\hline Poor & $79(20.5)$ & $46(11.9)$ & 0.672 & $0.252-1.792$ & 0.427 \\
\hline \multicolumn{6}{|l|}{ Health service utilization } \\
\hline Normal clinic visit ( $\leq 3 /$ year) & $90(23.4)$ & $82(21.3)$ & 1.0 & - & - \\
\hline High clinic visit ( $\geq 4 /$ year) & $127(33)$ & $86(22.3)$ & 1.260 & $0.767-2.070$ & 0.362 \\
\hline \multicolumn{6}{|l|}{ Health risks } \\
\hline Smoking & $97(25.2)$ & $75(19.5)$ & 1.0 & - & - \\
\hline Alcohol consumption & $\mathrm{I}(0.3)$ & $0(0.0)$ & - & - & 1.000 \\
\hline Obesity & $55(14.3)$ & $39(10.1)$ & 1.038 & $0.554-1.947$ & 0.907 \\
\hline None & $64(16.6)$ & $54(14.0)$ & 0.976 & $0.52 I-1.827$ & 0.940 \\
\hline \multicolumn{6}{|l|}{ Comorbidity } \\
\hline Present & $177(46)$ & $118(30.6)$ & 1.0 & - & - \\
\hline Absent & $40(10.4)$ & $50(13.0)$ & 0.707 & $0.409-1.222$ & 0.215 \\
\hline \multicolumn{6}{|l|}{ Number of drugs } \\
\hline$\leq 4$ & $49(12.7)$ & $78(20.3)$ & 1.0 & - & - \\
\hline Polypharmacy (5-9 days) & I 45 (37.7) & $89(23.1)$ & 2.556 & $1.579-4.135$ & $<0.001$ \\
\hline Excessive polypharmacy ( $\geq 10$ days) & $23(6.0)$ & $\mathrm{I}(0.3)$ & 37.828 & $4.754-300.9$ & $<0.001$ \\
\hline
\end{tabular}

Note: Bold values show statistical significance of differences.

Abbreviations: $\mathrm{Cl}$, confidence interval; $\mathrm{OR}$, odd ratio.

found in this study. Therefore, further studies are required for exploring these factors.

Thus, the rational use of medicines among geriatric patients requires their limited access toward PIMs. A multidisciplinary collaborative approach is needed for defining protocols pertaining to disease management and improving the QoL of elderly patients. As the negligence of PIMassociated health crises and unplanned hospitalization can economically burdened the society and the healthcare system, so it becomes mandatory for policy makers to 
formulate national action plan and healthcare professionals must implement international treatment guidelines in their routine practice.

\section{Strength and limitations}

To the best of our knowledge, this is the first study in Pakistan that gives an insight about the utilization of PIMs among elderly patients that lead to unplanned hospitalization. The previously published studies conducted in this region also had considered geriatrics as a risk population for the irrational use of medicines, but the spectrum of their findings was confined to the assessment of utilization pattern of PIMs either during hospitalization or after hospitalization. This study highlights the need of developing standard treatment protocols and implementing systematic drug-monitoring system.

The present study has some limitations. First, this is a cross-sectional study with small sample size and data were collected for short duration of time. Second, the defined daily doses of PIMs could not be calculated. Finally, the appropriateness was checked only for drug indications and interactions, while it was not considered for the duplication and duration of therapy, and directions of taking medicines was not taken into account, so the investigators were unable to evaluate that the hospitalization was the result of inappropriate use of PIMs or just having a report of using a PIM 7 days prior to admission.

\section{Conclusion}

The present study concluded that PIMs were commonly utilized among geriatric patients. The consumption of aspirin, omeprazole, insulin, and diphenhydramine had caused the unplanned hospitalization of these patients. This might be attributable to the unavailability of national standard treatment protocols and disobedience of international guidelines for elderly patients in Pakistan. The usage of these medicines is highly irrational and significantly associated with the advanced age and polypharmacy, while the age of geriatrics was found to be less likely correlated with unplanned hospitalization than the number of exposed medicines. Hence, caution must be exercised in prescribing PIMs listed in Beers criteria to the elderly patients.

\section{Acknowledgments}

We would like to express wholehearted thankfulness to the administration of all the selected settings of Lahore, Pakistan. We express gratitude to Dr Shane Scahill (senior lecturer, Massey University, New Zealand) for reviewing and editing the article and for valuable comments. No funding was involved in the preparation of this article or in the decision to submit it for publication.

\section{Author contributions}

MRS and SI conceptualized and designed the study. A-RD, SYM, TR, and UD analyzed and interpreted the data. SI, A-RD, SYM, TR, and UD drafted the article. MRS critically revised the article. All authors contributed toward data analysis, drafting and critically revising the paper and agree to be accountable for all aspects of the work. All authors read and approved final version of the article.

\section{Disclosure}

The authors report no conflicts of interest in this work.

\section{References}

1. Barry M. Drug expenditure in Ireland 1991-2001. Ir Med J. 2002; 95(10):294-295.

2. Chrischilles EA, Foley DJ, Wallace RB, et al. Use of medications by persons 65 and over: data from the established populations for epidemiologic studies of the elderly. J Gerontol. 1992;47(5):M137-M144.

3. Mannesse CK, Derkx FH, de Ridder MA, Man In 't Veld AJ, van der Cammen TJ. Contribution of adverse drug reactions to hospital admission of older patients. Age Ageing. 2000;29(1):35-39.

4. Simonson W, Feinberg JL. Medication-Related Problems in the Elderly. Drugs Aging. 2005;22(7):559-569.

5. Hohl CM, Dankoff J, Colacone A, Afilalo M. Polypharmacy, adverse drug-related events, and potential adverse drug interactions in elderly patients presenting to an emergency department. Ann Emerg Med. 2001; 38(6):666-671.

6. Veehof LJ, Stewart RE, Meyboom-de Jong B, Haaijer-Ruskamp FM. Adverse drug reactions and polypharmacy in the elderly in general practice. Eur J Clin Pharmacol. 1999;55(7):533-536.

7. Routledge PA, O'Mahony MS, Woodhouse KW. Adverse drug reactions in elderly patients. Br J Clin Pharmacol. 2004;57(2):121-126.

8. Campenelli C, American Geriatrics Society 2012 Beers Criteria Update Expert Panel. American Geriatrics Society updated Beers Criteria for potentially inappropriate medication use in older adults. $J$ Am Geriatr Soc. 2012;60(4):616-631.

9. Marcum ZA, Hanlon JT. Commentary on the new American Geriatric Society Beers criteria for potentially inappropriate medication use in older adults. Am J Geriatr Pharmacother. 2012;10(2):151-159.

10. Fessele KL, Hayat MJ, Mayer DK, Atkins RL. Factors associated with unplanned hospitalizations among patients with nonmetastatic colorectal cancers intended for treatment in the ambulatory setting. Nurs Res. 2016;65(1):24-34.

11. Zaveri HG, Mansuri SM, Patel VJ. Use of potentially inappropriate medicines in elderly: a prospective study in medicine out-patient department of a tertiary care teaching hospital. Indian J Pharmacol. 2010; 42(2):95.

12. Nishtala PS, Bagge ML, Campbell AJ, Tordoff JM. Potentially inappropriate medicines in a cohort of community-dwelling older people in New Zealand. Geriatr Gerontol Int. 2014;14(1):89-93.

13. Renom-Guiteras A, Meyer G, Thürmann PA. The EU(7)-PIM list: a list of potentially inappropriate medications for older people consented by experts from seven European countries. Eur J Clin Pharmacol. 2015; 71(7):861-875.

14. Price SD, Holman CD, Sanfilippo FM, Emery JD. Association between potentially inappropriate medications from the Beers criteria and the risk of unplanned hospitalization in elderly patients. Ann Pharmacother. 2014;48(1):6-16. 
15. Budnitz DS, Lovegrove MC, Shehab N, Richards CL. Emergency hospitalizations for adverse drug events in older Americans. N Engl J Med. 2011;365(21):2002-2012.

16. Schmader KE, Hanlon JT, Landsman PB, Samsa GP, Lewis IK, Weinberger M. Inappropriate prescribing and health outcomes in elderly veteran outpatients. Ann Pharmacother. 1997;31(5):529-533.

17. Runciman WB, Roughead EE, Semple SJ, Adams RJ. Adverse drug events and medication errors in Australia. Int $J$ Qual Health Care. 2003;15(90001):49i-59i.

18. Gallagher P, Barry P, O'Mahony D. Inappropriate prescribing in the elderly. J Clin Pharm Ther. 2007;32(2):113-121.

19. Hamilton HJ, Gallagher PF, O’Mahony D. Inappropriate prescribing and adverse drug events in older people. BMC Geriatr. 2009;9(1):5.

20. Laroche ML, Charmes JP, Bouthier F, Merle L. Inappropriate medications in the elderly. Clin Pharmacol Ther. 2009;85(1):94-97.

21. Passarelli MCG, Jacob-Filho W, Figueras A. Adverse drug reactions in an elderly hospitalised population. Drugs Aging. 2005;22(9): 767-777.

22. Page RL, Linnebur SA, Bryant LL, Ruscin JM. Inappropriate prescribing in the hospitalized elderly patient: defining the problem, evaluation tools, and possible solutions. Clin Interv Aging. 2010;5:75.

23. Matanović SM, Vlahović-Palčevski V. Potentially inappropriate prescribing to the elderly: comparison of new protocol to Beers criteria with relation to hospitalizations for ADRs. Eur J Clin Pharmacol. 2014; 70(4):483-490.

24. Beers MH, Ouslander JG, Rollingher I, Reuben DB, Brooks J, Beck JC. Explicit criteria for determining inappropriate medication use in nursing home residents. UCLA Division of Geriatric Medicine. Arch Intern Med. 1991;151(9):1825-1832.

25. Beers MH. Explicit criteria for determining potentially inappropriate medication use by the elderly. An update. Arch Intern Med. 1997;157(14): $1531-1536$

26. Sehgal V, Bajwa SJ, Sehgal R, Bajaj A, Khaira U, Kresse V. Polypharmacy and potentially inappropriate medication use as the precipitating factor in readmissions to the hospital. J Family Med Prim Care. 2013; 2(2): 194 .

27. Jalal S, Younis MZ. Aging and elderly in Pakistan. Ageing Int. 2014; 39(1):4-12.

28. Zafar SN, Ganatra HA, Tehseen S, Qidwai W. Health and needs assessment of geriatric patients: results of a survey at a teaching hospital in Karachi. J Pak Med Assoc. 2006;56(10):470.

29. Wikipedia [webpage on the Internet].2017 Census of Pakistan;2017. Available from: https://en.wikipedia.org/wiki/2017_Census_of_Pakistan. Accessed March 29, 2018.

30. [webpage on the Internet]. Raosoft; 2004. Available from: http://www. raosoft.com/samplesize.html. Accessed March 29, 2018.

31. Pappa E, Kontodimopoulos N, Papadopoulos AA, Tountas Y, Niakas D. Prescribed-drug utilization and polypharmacy in a general population in Greece: association with sociodemographic, health needs, healthservices utilization, and lifestyle factors. Eur J Clin Pharmacol. 2011; 67(2):185-192.

32. World Health Organization. The Anatomical Therapeutic Chemical Classification System With Defined Daily Doses (ATC/DDD). Oslo: WHO; 2006.

33. Panel AGSBCUE, Fick DM, Semla TP, By the American Geriatrics Society 2015 Beers Criteria Update Expert Panel. American Geriatrics Society 2015 updated Beers criteria for potentially inappropriate medication use in older adults. J Am Geriatr Soc. 2015;63(11): 2227-2246.

34. CFDCAP. International Classification of Diseases, Ninth Revision, Clinical Modification (ICD-9-CM); 2015.

35. Sah AK, Jha RK, Sah P, Basnet S. Potentially inappropriate prescribing in elderly population: a study in medicine out-patient department. J Coll Med Sci - Nepal. 2017;13(1):197-202.
36. Budnitz DS, Shehab N, Kegler SR, Richards CL. Medication use leading to emergency department visits for adverse drug events in older adults. Ann Intern Med. 2007;147(11):755-765.

37. Mazhar F, Akram S, Malhi SM, Haider N. A prevalence study of potentially inappropriate medications use in hospitalized Pakistani elderly. Aging Clin Exp Res. 2018;30(1):53-60.

38. Schepisi R, Fusco S, Sganga F, et al. Inappropriate use of proton pump inhibitors in elderly patients discharged from acute care hospitals. J Nutr Health Aging. 2016;20(6):665-670.

39. Sarwar MR, Atif M, Scahill S, Saqib A, Qamar-Uz-Zaman M, Babar Z. Drug utilization patterns among elderly hospitalized patients on polypharmacy in Punjab, Pakistan. J Pharm Policy Pract. 2017;10(1):23.

40. Saqib A, Atif M, Scahill S. Drug utilization evaluation among an elderly population: a retrospective cross-sectional study in a tertiary care hospital in Pakistan. J Pharm Health Serv Res. 2018;9(2):123-132.

41. Pitkala KH, Strandberg TE, Tilvis RS. Inappropriate drug prescribing in home-dwelling, elderly patients: a population-based survey. Arch Intern Med. 2002;162(15):1707-1712.

42. Kidwai R, Ahmed SH. Prevalence of insomnia and use of sleep medicines in urban communities of Karachi, Pakistan. J Pak Med Assoc. 2013; 63(11):1358-1363.

43. Saleem A, Khan TM. Medication misuse among elderly population in Pakistan. Ther Adv Drug Saf. 2016;7(3):122-123.

44. Reich O, Rosemann T, Rapold R, Blozik E, Senn O. Potentially inappropriate medication use in older patients in Swiss managed care plans: prevalence, determinants and association with hospitalization. PLoS One. 2014;9(8):e105425.

45. Vieira de Lima TJ, Garbin CA, Garbin AJ, Sumida DH, Saliba O. Potentially inappropriate medications used by the elderly: prevalence and risk factors in Brazilian care homes. BMC Geriatr. 2013;13(1):52.

46. Endres HG, Kaufmann-Kolle P, Steeb V, Bauer E, Böttner C, Thürmann P. Association between potentially inappropriate medication (PIM) use and risk of hospitalization in older adults: an observational study based on routine data comparing PIM use with use of PIM alternatives. PLoS One. 2016;11(2):e0146811.

47. Jeon HL, Park J, Han E, Kim DS. Potentially inappropriate medication and hospitalization/emergency department visits among the elderly in Korea. Int J Qual Health Care. 2018;30(1):50-56.

48. Bao Y, Shao H, Bishop TF, Schackman BR, Bruce ML. Inappropriate medication in a national sample of US elderly patients receiving home health care. J Gen Intern Med. 2012;27(3):304-310.

49. Osei EK, Berry-Cabán CS, Haley CL, Rhodes-Pope H. Prevalence of Beers Criteria Medications Among Elderly Patients in a Military Hospital. Gerontol Geriatr Med. 2016;2:2333721416637790.

50. Vds M, Mori A, Dorea EL, et al. Exposure to potentially inappropriate medications in Brazilian elderly outpatients with metabolic diseases. Bra J Pharm Sci. 2016;52(4):699-707.

51. Pradhan S, Panda A, Mohanty M, Behera JP, Ramani YR, Pradhan PK. A study of the prevalence of potentially inappropriate medication in elderly in a tertiary care teaching hospital in the state of Odisha. Int J Med Public Health. 2015;5(4):344.

52. Chang CB, Yang SY, Lai HY, et al. Application of three different sets of explicit criteria for assessing inappropriate prescribing in older patients: a nationwide prevalence study of ambulatory care visits in Taiwan. BMJ Open. 2015;5(11):e008214.

53. Zeenny R, Wakim S, Kuyumjian YM. Potentially inappropriate medications use in community-based aged patients: a cross-sectional study using 2012 Beers criteria. Clin Interv Aging. 2017;12:65-73.

54. Alomar MJ. Factors affecting the development of adverse drug reactions (Review article). Saudi Pharm J. 2014;22(2):83-94.

55. Dewalt DA, Berkman ND, Sheridan S, Lohr KN, Pignone MP. Literacy and health outcomes. J Gen Intern Med. 2004;19(12):1228-1239. 
Clinical Interventions in Aging

\section{Publish your work in this journal}

Clinical Interventions in Aging is an international, peer-reviewed journal focusing on evidence-based reports on the value or lack thereof of treatments intended to prevent or delay the onset of maladaptive correlates of aging in human beings. This journal is indexed on PubMed Central, MedLine,

CAS, Scopus and the Elsevier Bibliographic databases. The manuscript management system is completely online and includes a very quick and fair peer-review system, which is all easy to use. Visit http://www.dovepress. $\mathrm{com} /$ testimonials.php to read real quotes from published authors.

Submit your manuscript here: http://www.dovepress.com/clinical-interventions-in-aging-journal 